\title{
Of energy and survival incognito: a relationship between viable but non-culturable cells formation and inorganic polyphosphate and formate metabolism in Campylobacter jejuni
}

\author{
Issmat I. Kassem, Kshipra Chandrashekhar and Gireesh Rajashekara* \\ Food Animal Health Research Program, Ohio Agricultural Research and Development Center, Department of Veterinary Preventive Medicine, \\ The Ohio State University, Wooster, OH, USA
}

\section{Edited by:}

Nuno Pereira Mira, Instituto Superior Técnico; Institute for Biotechnology and Bioengineering, Portugal

\section{Reviewed by:}

Ulrike Kappler, University of Queensland, Australia

Patricia Coutinho Dos Santos, Wake

Forest University, USA

Paula Teixeira, Universidade Católica

Portuguesa, Portugal

\section{*Correspondence:}

Gireesh Rajashekara, Food Animal

Health Research Program, Ohio

Agricultural Research and

Development Center, Department of

Veterinary Preventive Medicine,

The Ohio State University, Food

Animal Health Building, 1680

Madison Avenue, Wooster,

$\mathrm{OH} 44691$, USA

e-mail: rajashekara.2@osu.edu
Campylobacter jejuni is a Gram-negative food-borne bacterium that can cause mild to serious diseases in humans. A variety of stress conditions including exposure to formic acid, a weak organic acid, can cause $C$. jejuni to form viable but non-culturable cells (VBNC), which was proposed as a potential survival mechanism. The inability to detect C. jejuni VBNC using standard culturing techniques may increase the risk of exposure to foods contaminated with this pathogen. However, little is known about the cellular mechanisms and triggers governing VBNC formation. Here, we discuss novel mechanisms that potentially affect VBNC formation in $C$. jejuni and emphasize the impact of formic acid on this process. Specifically, we highlight findings that show that impairing inorganic polyphosphate (poly-P) metabolism reduces the ability of $C$. jejuni to form VBNC in a medium containing formic acid. We also discuss the potential effect of poly- $P$ and formate metabolism on energy homeostasis and cognate VBNC formation. The relationship between poly-P metabolism and VBNC formation under acid stress has only recently been identified and may represent a breakthrough in understanding this phenomenon and its impact on food safety.

Keywords: viable but non-culturable cells, Campylobacter jejuni, inorganic polyphosphate, polyphosphate kinase, formate metabolism, formate dehydrogenase, acid stress, energy

\section{ENTER VBNC: A BRIEF HISTORY, SIGNIFICANCE, AND CONTROVERSY}

Researchers in 1982 observed that two bacterial species, Escherichia coli and Vibrio cholerae, could not be retrieved from saltwater microcosms using a medium that previously sustained their growth (Xu et al., 1982). Although these bacterial species lost culturability in response to stress, they still maintained detectable metabolic activity, which suggested that these cells were still viable (Xu et al., 1982). Based on these observations, researchers suggested that stressed bacterial cells might exist in a viable but non-culturable (VBNC) state (Colwell et al., 1985; Oliver, 2010). Since the initial discovery, there have been hundreds of publications documenting VBNC formation in a variety of bacterial species, including important pathogens such as Helicobacter pylori, V. cholerae, Campylobacter jejuni, and others (Oliver, 2005). Further, it was shown that VBNC can be induced under different stresses, including exposure to chlorine, acids, oxygen, and pasteurization as well as those associated with fluctuations in the environment's salinity, $\mathrm{pH}$, and temperature (Chaveerach et al., 2003; Oliver, 2005). Today, VBNC are broadly defined as cells that enter a non-culturable state in response to stress, while maintaining a detectable but reduced metabolism (e.g., decrease in respiration, nutrient transportation, and synthesis of macromolecules), relatively high ATP levels, and aspects of cellular integrity such as intact chromosome content and cell membrane (Grégori et al., 2001; Oliver, 2005, 2010). Additional VBNC characteristics also occasionally include changes to cell morphology such as "rounding up" and reduction in the size of the cells, which is thought to maximize the surface area available for nutrient uptake while minimizing cell mass (Colwell, 2000; Oliver, 2005). It is important to note that the VBNC state may differ from other survival mechanisms. For example, in Enterococcus faecalis, the proteomic profiles of starved cells were observed to be different from those of the VBNC (Heim et al., 2002), which potentially indicated that the latter was triggered only in response to certain stresses.

With increasing knowledge about VBNC, their significance as a potential risk for public health became evident. A major concern is the inability to detect pathogens in the VBNC state using standard culture-based techniques. This is significant, because VBNC can potentially retain virulence and can be resuscitated back to "normal"/culturable physiological state under favorable conditions, including those available within hosts (Oliver, 2005, 2010). Subsequently, this may increase the potential for undetectable contamination and the spread of infectious agents to susceptible hosts. Although this is a contentious issue with arguments and research either supporting or disproving the ability of VBNC to cause disease in hosts, it is important to note that the possibility for infection should not be merely disregarded (Oliver, 2005, 2010). The lack 
of complete knowledge in regards to VBNC's virulence, factors influencing their resuscitation, and cognate public health risks and ramifications might at the very least provide supportive impetus for prudence when considering risks associated with VBNC. In fact, under certain scenarios, potential risks may weigh heavily and can pose a severe threat to public welfare. For example, VBNC contamination of food products (Rowan, 2004; Dinu and Bach, 2011) and medical equipment (Zandri et al., 2012) can go undetected, impacting consumers, jeopardizing the safety of food, and threatening the lives of susceptible patients.

Of particular interest for food safety is C. jejuni, a food-borne pathogen that can form VBNC under stress (Rollins and Colwell, 1986; Jackson et al., 2009). C. jejuni is a Gram-negative bacterium that can cause disease in humans, including gastroenteritis and occasionally debilitating and life-threatening neuropathies (Vandamme and De Ley, 1991; On, 1996). The control of C. jejuni in poultry and other food animals and products (e.g., beef, turkey, and milk) has proved to be challenging, due in part to the atypical pathobiology of this bacterium, which lacks many of the classical stress response factors associated with other enteric pathogens (Parkhill et al., 2000). This singularity of C. jejuni necessitates a closer consideration of all its possible survival strategies, including VBNC formation; in order to enhance on-going efforts to reduce this pathogen in foods. This viewpoint is supported by research showing that C. jejuni VBNC can adhere to the skin of chicken carcasses (Jang et al., 2007), while a recent study reported that $C$. jejuni VBNC can still express a protein ( CadF) that facilitates its attachment to host cells (Patrone et al., 2013). Further, it was also shown that C. jejuni VBNC can colonize suckling mice (Jones et al., 1991). Therefore, in this minireview, we will briefly discuss some of the molecular factors involved in VBNC formation in bacteria and focus in more detail on $C$. jejuni, highlighting recent research that associates specific metabolic pathways with VBNC formation in this important pathogen.

\section{UNTHREADING THE MYSTERY: GENETIC FACTORS INVOLVED IN VBNC FORMATION AND VIRULENCE}

To date, many of the cellular triggers and genetic factors involved in VBNC formation are not well understood. However, increasing research into this phenomenon has revealed glimpses of potential factors that are likely involved in the persistence and expression of virulence in VBNC. Notably, it has been reported that gene expression in VBNC can continue for extended periods of time; for instance, the cytotoxin-hemolysin ( $\left.v v_{h} A\right)$ transcripts were detected in VBNC of $V$. vulnificus for up to 4.5 months (Saux et al., 2002). Although it is not clear if these expressed genes are directly involved in VBNC formation, the latter example highlights the possibility for maintaining virulence in the VBNC state. Further, many studies reported the expression of virulence-associated genes in VBNC of other pathogens. For example, in a recent study the expression of $c a d F$, a gene that encodes an outer membrane protein that facilitates binding to fibronectin in host cells, was detected at high levels in C. jejuni VBNC for 3 weeks (Patrone et al., 2013). In parallel to these observations, the authors also reported that C. jejuni VBNC were capable of adhering to intestinal cells in vitro, but at levels that were lower than that of the culturable strain (Patrone et al., 2013). In another study, virulence-associated genes, including those encoding flagellin proteins, the cytolethal distending toxin, and a Campylobacter invasion antigen that are involved in invading- / interacting with the host's intestinal cells were found to maintain a low level of expression in C. jejuni VBNC (Chaisowwong et al., 2012). Similarly, the mRNA of the Shiga toxin encoding gene (stx1) was detected in VBNC of E. coli O157:H7 (Yaron and Matthews, 2002), which is a notable finding because these toxins are associated with hemorrhagic colitis, hemolytic uremic syndrome, thrombocytopenia, hemolytic anemia, and renal failure (Karmali, 1989). Coccoid-shaped cells of $V$. cholerae entering a VBNC state were found to express the toxin co-regulated pilus (TCP), a virulence factor that is important for colonization of the small intestine in humans, and were able to colonize infant mice (Krebs and Taylor, 2011). The authors also noted that in a previous study TCP like appendages could be seen in micrographs of 1 year old V. cholerae VBNC (Chaiyanan et al., 2007). Another investigation detected viable-non-culturable and coccoid-shaped cells of $H$. pylori in biopsies collected from 12 dyspeptic patients, and these cells expressed $\operatorname{luxS}$, a gene associated with quorum sensing and bacterial virulence (Cellini et al., 2008). Collectively, the aforementioned studies and other published research (Table 1) support the ability of VBNC to maintain some aspects of virulence and/or regain them after resuscitation.

It was shown that two regulatory genes ( $\operatorname{alg} U$ and $g a c A)$ that code for the alternative sigma factor $\left(\sigma^{E}\right)$ and a response regulator, respectively, may be involved in VBNC formation in Pseudomonas fluorescens CHA0, which is used as a biocontrol agent against black root rot (Mascher et al., 2002). Additionally, it was suggested that resuscitation-promoting factor ( $\mathrm{Rpf}$ )-like proteins might be involved in the reactivation of non-culturable cells of the human pathogen Mycobacterium tuberculosis (Shleeva et al., 2002). A delay in VBNC formation in an S. Typhimurium LT2 mutant was associated with a 99-bp in-frame deletion in the clpX gene, which is known to be involved in forming a protease complex that degrades the general stress sigma factor RpoS (Kusumoto et al., 2013). Subsequently, the authors suggested that this ClpX-RpoS relationship might have affected entry into the VBNC state (Kusumoto et al., 2013). Further, RpoS expression was detected for up to 14 days in VBNC of $V$. vulnificus (Smith and Oliver, 2006), while this stress factor was implicated in the persistence of $E$. coli in a VBNC state (Boaretti et al., 2003). In another study, the inactivation of OxyR, an oxygen stress regulator, and the cognate catalase enzyme impacted VBNC formation in V. vulnificus (Kong et al., 2004). Collectively, these are very interesting findings and can potentially shed light on the VBNC state of important pathogens and beneficial bacteria; however, this also raises several important questions. For example, the atypical pathogen, C. jejuni, has substantially documented VBNC state but lacks RpoS, OxyR, and a $\sigma^{E}$ response (van Vliet et al., 1999; Parkhill et al., 2000), while investigations of a potential C. jejuni resuscitation factor (Cj0645) in strain NCTC11168 showed that the target was not an Rpf ortholog (Morgan, 2010). These observations suggest that the aforementioned genes may not necessarily be a factor in all VBNC-forming pathogens, which raises the following question: could there be a ubiquitously distributed cellular mechanism that might affect VBNC formation across many species? This question can perhaps be partially addressed by recent findings (detailed below) that 


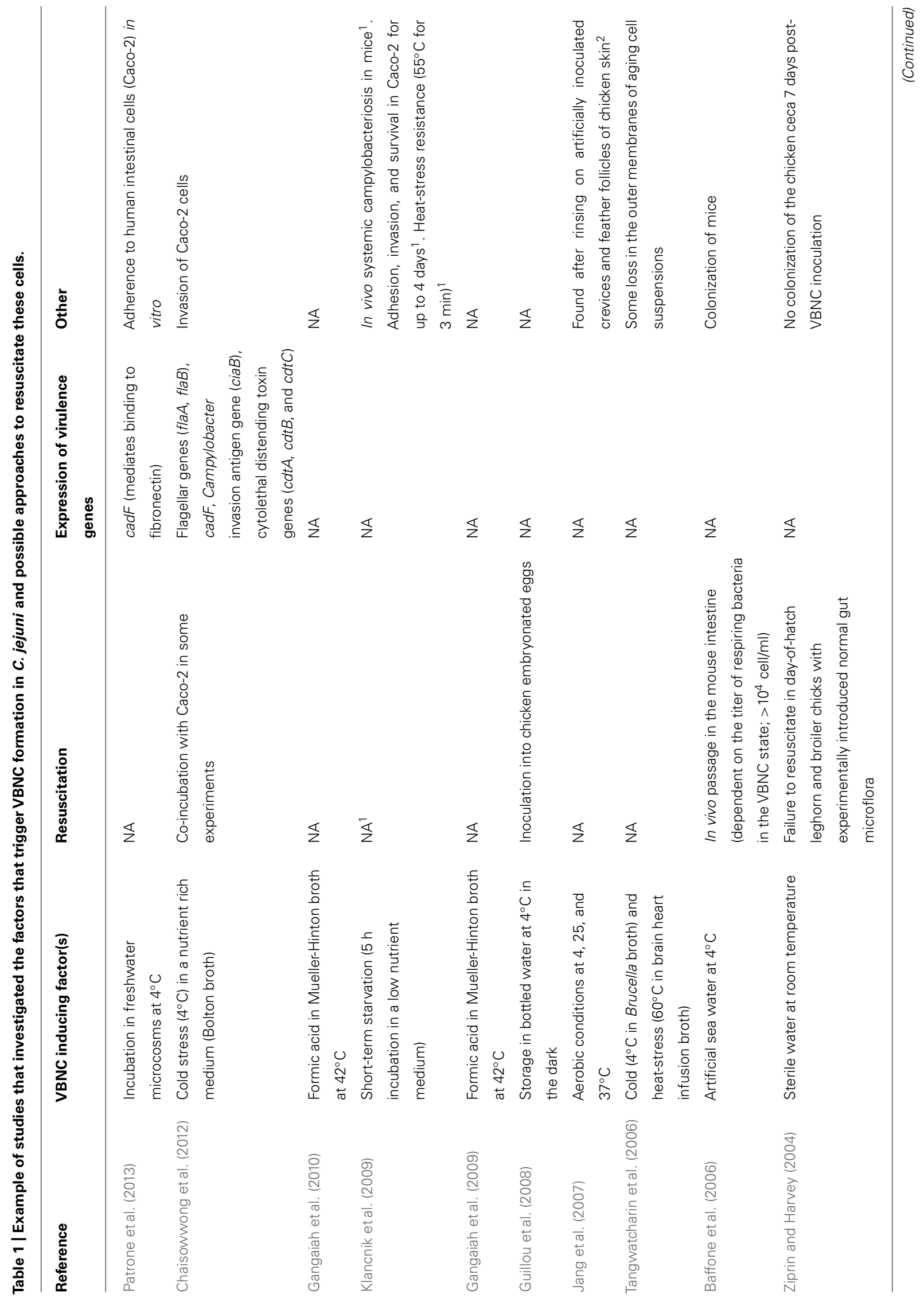




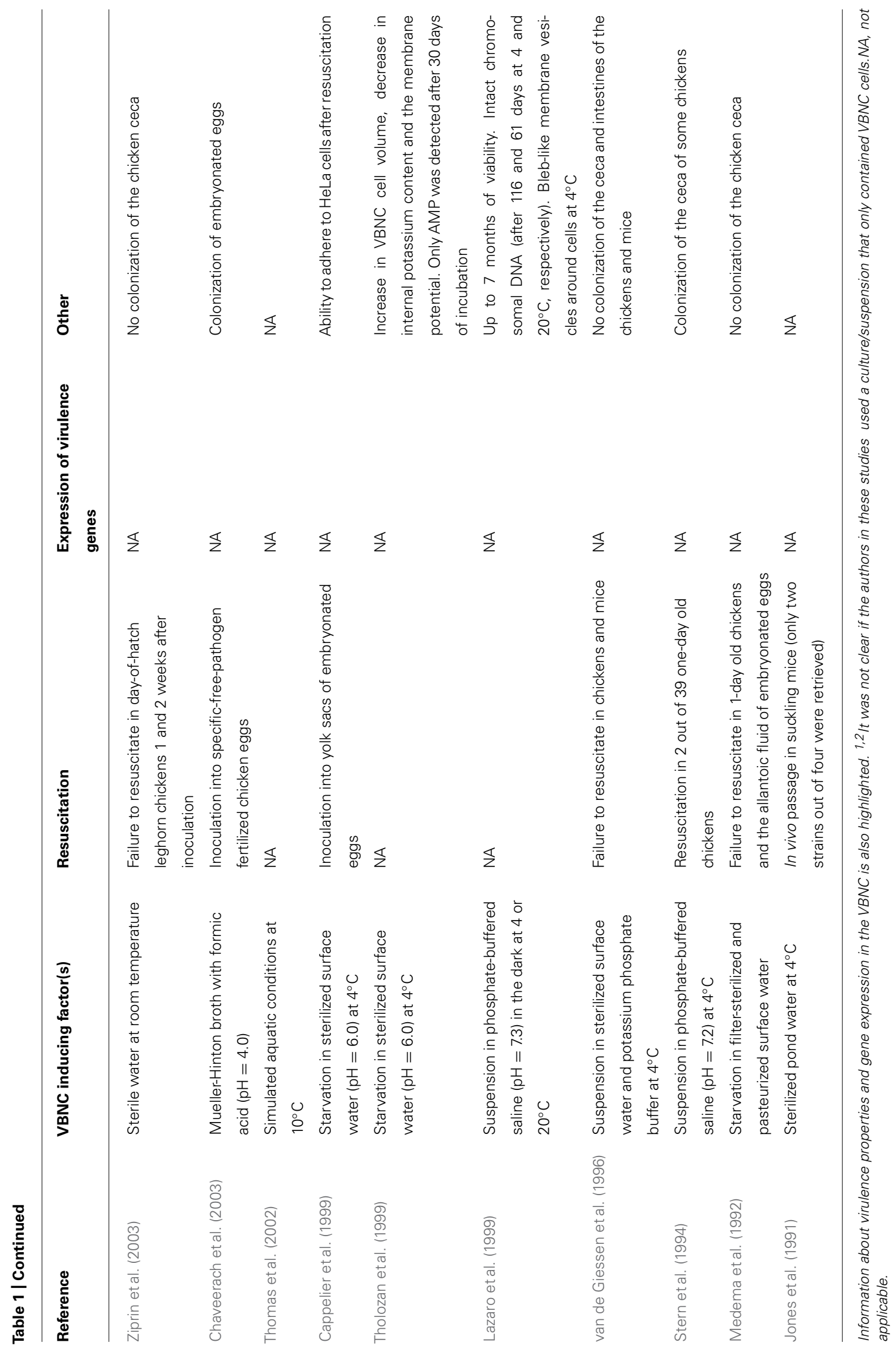


link VBNC formation in C. jejuni to the metabolism of inorganic polyphosphate (poly-P), an ancient molecule that is ubiquitous in bacteria and plays a role in energy storage and production (Kornberg et al., 1999; Rao et al., 2009).

Despite the current gaps in knowledge, the studies highlighted previously present a convincing case for researching the virulence of VBNC and their potential impact on public health. This might be of critical relevance when considering the survival mechanisms of atypical pathogens such as $C$. jejuni and cognate ramifications to public health, including food safety.

\section{OF ENERGY AND VBNC: A RELATIONSHIP BETWEEN C. jejuni VBNC FORMATION AND INORGANIC POLYPHOSPHATE METABOLISM}

Most of the past work that focused on C. jejuni VBNC mainly described the physical, chemical, and environmental triggers that induce this state such as exposure to oxygen, persistence in aquatic microcosms, changes in temperature and $\mathrm{pH}$, and starvation (Jackson et al., 2009; Table 1). In addition, there was an emphasis on strategies aiming at resuscitation of $C$. jejuni VBNC in vitro or in vivo (Bovill and Mackey, 1997; Cappelier et al., 1999; Chaveerach et al., 2003; Baffone et al., 2006; Table 1). Like in many VBNCforming bacteria, the genetic mechanisms that are associated with the VBNC state of C. jejuni are largely unknown. However, it was recently shown that VBNC formation in C. jejuni might be impacted by proteins involved in the metabolism of inorganic poly-P. Specifically, poly-P is a linear polymer of orthophosphate residues that plays a vital role in $C$. jejuni and other bacteria as a source of ATP for approximately 500 cellular reactions and as a modulator of stress and survival phenotypes (Kornberg et al., 1999; Rao etal., 2009; Kassem and Rajashekara, 2011). Since (1) maintaining cellular respiration and relatively high ATP levels are two major features of the VBNC state, (2) conserving energy is a basic survival strategy under stress, and (3) C. jejuni, a bacterium with relatively small genome that lacks typical stress responses, has invested in retaining a network of enzymes associated with poly-P metabolism, a link between the poly-P molecule and C. jejuni VBNC appeared to be plausible. The latter mandated a closer look at $C$. jejuni that revealed that this pathogen possessed two major enzymes, namely polyphosphate kinase 1 (PPK1) and polyphosphate kinase 2 (PPK2), which are principally involved in the synthesis/accumulation of poly-P and associated GTP production, respectively (Gangaiah et al., 2009, 2010). The inactivation of these enzymes leads to pleiotropic effects, influencing different survival phenotypes in C. jejuni (Gangaiah et al., 2009, 2010). Notably, live/dead cell staining analysis showed that the C. jejuni deletion mutants, $\triangle p p k 1$ and $\triangle p p k 2$, possessed a significantly reduced ability to form VBNC after challenge with formic acid (Gangaiah et al., 2009, 2010). This was confirmed using flow cytometry analysis that revealed a significant change in the cell size and granularity of the $\Delta p p k 1$ mutant as compared to the parental strain (Gangaiah et al., 2009), possibly indicating an increase in dead cells in the acid-stressed mutants (Kusters et al., 1997). While investigating the expression of a number of genes that were believed to contribute to the phenotypes of the $\Delta p p k 1$ mutant, it was found that the phosphate regulon genes (phosR, $p s t S$, pst $C$, and the periplasmic substrate binding protein-encoding gene, CJJ81176_0750), the multidrug resistance efflux pump gene ( $c m e C)$, the global post-transcriptional regulator $(\operatorname{csr} A)$, and the stringent response regulator (spoT) were not affected in the acidstressed mutant cells (Gangaiah et al., 2009). However, $p p k 2$ was significantly down regulated in the formic acid challenged $\Delta p p k 1$ mutant, but the expression of $p p k 2$ was not affected in similarly treated wild-type cells, which further implicates the $p p k s$ in C. jejunis VBNC formation (Gangaiah etal., 2009). Since the $\Delta p p k 1$ mutant was deficient in the accumulation of poly-P and the $p p k 2$ down regulation would possibly reduce the associated GTP production (Gangaiah et al., 2009), the aforementioned observations suggest that the poly-P-dependent ATP/GTP pools and ratios in the $p p k$ mutants might be deficient as compared to that of the parental strain. This assumption is supported by the lower levels of poly-P-dependent GTP and the higher ATP:GTP ratios that were detected in the $\Delta p p k 2$ cells using thin layer chromatography analysis (Gangaiah et al., 2010). Therefore, it appears that the disruption of the poly-P associated enzymes creates an imbalance in the cellular poly-P-dependent ATP/GTP homeostasis, hence affecting the ability of $C$. jejuni to enter the VBNC state. Notably, it was shown that a putative ATP synthase was down regulated in the VBNC of Enterococcus faecalis (Heim et al., 2002), which prompted the speculation that the survival of VBNC under unfavorable conditions required alternative metabolic pathways to maintain energy (Heim et al., 2002). This possibly includes using energy that was stored as poly-P, further suggesting that an intact poly-P metabolism is essential for VBNC formation/ persistence.

It was reported that poly-P occurs in starved and morphologically altered V. parahaemolyticus (Chen et al., 2009), and this molecule also accumulated in structurally intact coccoid forms of starved H. pylori (Nilsson et al., 2002). However, no direct mechanistic association between poly-P and the formation of VBNC has been described previously. Although further studies are needed to formulate a comprehensive mechanistic model of the involvement of poly- $\mathrm{P}$ and its enzymes in VBNC formation, the advances highlighted above might direct and facilitate future research into the VBNC state.

\section{THE FORMATE CONNECTION: FORMATE METABOLISM AND VBNC FORMATION IN C. jejuni}

The findings linking poly-P to VBNC formation in C. jejuni will generate many extrapolations and questions. For example, the ATP/GTP pools in the cell are not only affected by poly-P and its enzymes; hence, could there be other factors impacting this pool and also contributing to VBNC formation in C. jejuni? Further, the $\triangle p p k 2$ mutant only responded to formic acid with reduced VBNC formation as compared to the parental strain, however, there was no difference in the colony forming units (CFU) counts between the mutant and the wild-type after challenge with other organic acids (acetic acid and propionic acid) and hydrochloric acid (Gangaiah et al., 2010). Could the latter observation suggest some specific relationship between formic acid and VBNC formation in C. jejuni? As a matter of fact, the previous two questions are intimately linked, because $C$. jejuni possesses a highly branched respiratory chain that serves in energy production 
(Myers and Kelly, 2004), while one of the major energy sources for this bacterium is formate that is metabolized by the periplasmic respiratory protein, formate dehydrogenase (Hoffman and Goodman, 1982; Weerakoon et al., 2009). This is not surprising because formate is a byproduct of fermentation that occurs in the hosts' gut, which is the preferable niche for C. jejuni (Weerakoon et al., 2009). It was also reported that the inactivation of the formate dehydrogenase $(f d h)$ in this bacterium resulted in round shaped cells similar to those associated with the VBNC (Figure 1A); however, the $f d h$ mutant did not lose culturability under normal growth conditions (Kassem et al., 2012). Further, when the fdh mutant was challenged with formic acid as described earlier, it showed a significant decrease in culturability and viability as compared to the wild-type, indicating a severe inability to form VBNC (unpublished data; Figure 1B). Therefore, it can be concluded

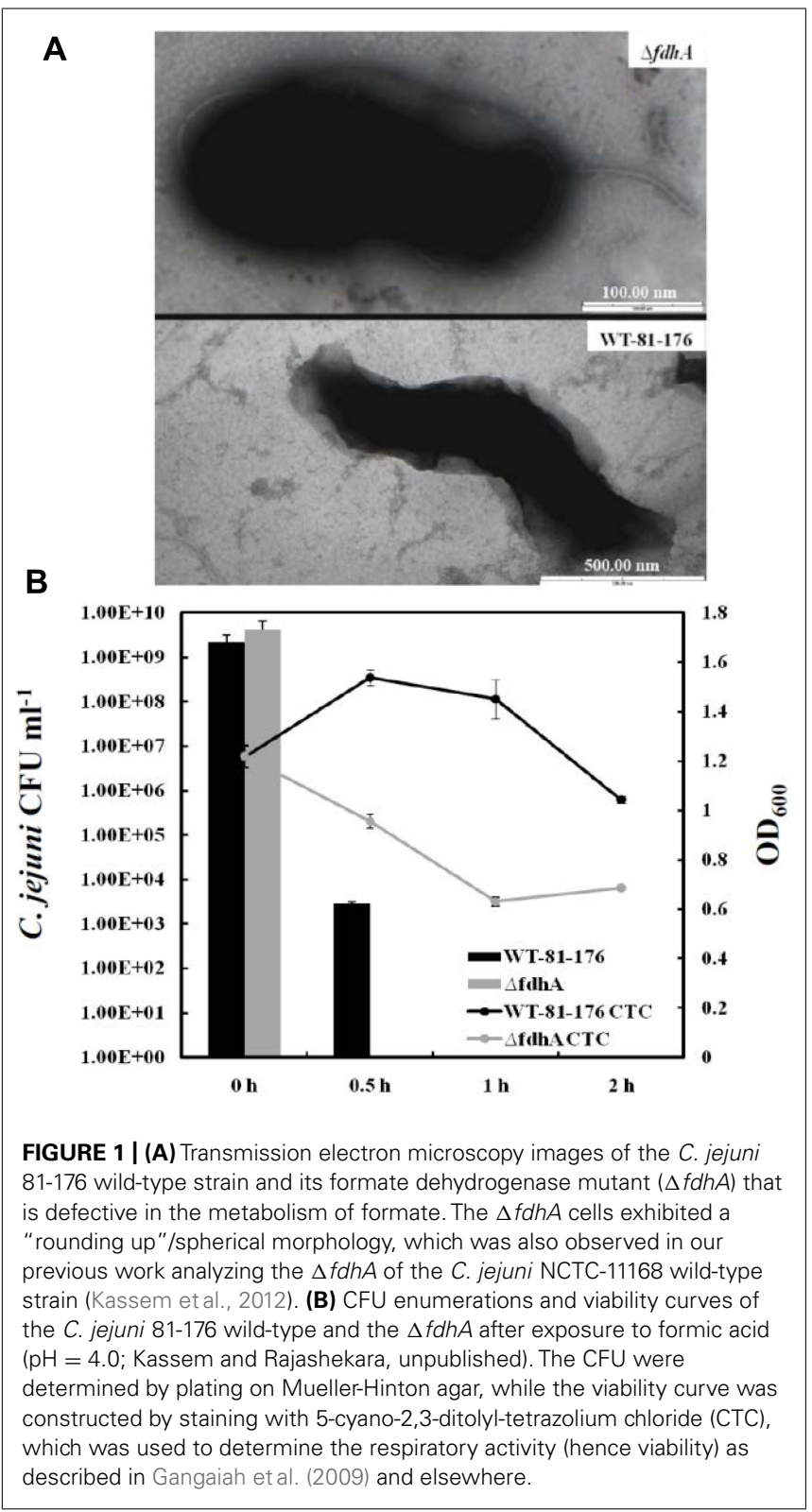

that formate dehydrogenase and formate metabolism are associated with VBNC formation in C. jejuni, likely via their role in energy production. Along these lines, a question worthy of investigation is whether the energy produced by formate metabolism may be linked to poly-P accumulation/degradation? Regardless, both the formate and poly-P metabolism are associated with energy and VBNC production in C. jejuni, further confirming the role of energy conservation in VBNC formation and subsequent survival.

\section{COVETED POTENTIALS: CONCLUSIONS AND CLOSING REMARKS}

It has been reported that poly-P and cognate enzymes occur in many bacterial species, suggesting that poly-P metabolism might be ubiquitous in the prokaryotes (Kornberg et al., 1999; Rao et al., 2009). Further, many of these species have a confirmed ability to enter the VBNC state (Table 2), which increases the appeal of a possible VBNC-poly-P link as a potential universal denominator in the formation of this cellular state. While the latter needs further experimental proof, poly-P appears to be a contributor to VBNC formation in the unconventional C. jejuni. Subsequently, the bearings of the findings listed above on efforts aiming at reducing C. jejuni in the food chain might be important, because it is already known that $C$. jejuni VBNC can adhere to edible products (e.g., on the skin of chicken carcasses; Jang et al., 2007). Further, phosphate-containing chemicals and weak organic acids (e.g., acetate and formate) have either been typically used or investigated as means to process, preserve, or decontaminate foods (Sofos and Smith, 1998; Capita et al., 2002; Hirshfield et al., 2003; Ricke, 2003). Organic acids, including formic acid, have also been used or tested as potential feed additives to reduce food-borne pathogens in animals including chickens, the primary reservoir of C. jejuni

Table 2 | A list of food-borne bacterial pathogens that possess homologs of the PPK enzymes (Rao et al., 2009).
VBNC-forming food-borne bacteria

Campylobacter jejuni

Campylobacter coli

Enterococcus faecalis

Escherichia coli

Helicobacter pylori

Salmonella enterica serovar, Enteritidis

S. Typhimurium

Shigella dysenteriae type 1

Shigella flexneri

Vibrio cholerae

Vibrio parahaemolyticus

Yersinia enterocolitica

\section{Polyphosphate kinase 1 (PPK1)} and PPK2 homologs
PPK1, PPK2
PPK1, PPK2
PPK1
PPK1, PPK2
PPK1
PPK1
PPK1
PPK1
PPK1
PPK1, PPK2
PPK1, PPK2
PPK1

These species/strains also have a documented ability to form VBNC (Rowan, 2004). 
(Ricke, 2003). However, these chemicals might be inducers or modulators for the food-borne pathogen to enter the difficult-todetect VBNC state.

Admittedly, the role of VBNC in the spread of food-related infections is not clear; however, it can be argued that caution is warranted in scenarios that involve food safety. Therefore, investigations on VBNC regarding (a) factors that trigger their formation, (b) mechanisms of their formation, (c) their virulence properties, and (d) conditions that favor their infectivity are important for

\section{REFERENCES}

Baffone, W., Casaroli, A., Citterio, B., Pierfelici, L., Campana, R., Vittoria, E., et al. (2006). Campylobacter jejuni loss of culturability in aqueous microcosms and ability to resuscitate in a mouse model. Int. J. Food Microbiol. 107, 8391. doi: 10.1016/j.ijfoodmicro.2005. 08.015

Boaretti, M., del Mar Lleo, M., Bonato, B., Signoretto, C., and Canepari, P. (2003). Involvement of rpoS in the survival of Escherichia coli in the viable but non-culturable state. Environ. Microbiol. 5, $986-$ 996. doi: 10.1046/j.1462-2920.2003. 00497.x

Bovill, R. A., and Mackey, D. B. (1997). Resuscitation of 'non-culturable' cells from aged cultures of Campylobacter jejuni. Microbiology 143, 1575-1581. doi: 10.1099/00221287-143-5-1575

Capita, R., Alonso-Calleja, C., GarciaFernandez, M. C., and Moreno, B. (2002). Review: trisodium phosphate (TSP) treatment for decontamination of poultry. Food Sci. Technol. Int. 8, 11-24. doi: 10.1106/ 108201302023118

Cappelier, J. M., Minet, J., Magras, C., Colwell, R. R., and Federighi, M. (1999). Recovery in embryonated eggs of viable but nonculturable Campylobacter jejuni cells and maintenance of ability to adhere to HeLa cells after resuscitation. Appl. Environ. Microbiol. 65, 5154-5157.

Cellini, L., Grande, R., Di Campli, E., Traini, T., Di Giulio, M., Nicola Lannutti, S., et al. (2008). Dynamic colonization of Helicobacter pylori in human gastric mucosa. Scand. J. Gastroenterol. 43, 178-185. doi: 10.1080/00365520701675965

Chaisowwong, W., Kusumoto, A., Hashimoto, M., Harada, T., Maklon, K., and Kawamoto, K. (2012). Physiological characterization of Campylobacter jejuni under cold stresses conditions: its potential for public threat. J. Vet. Med. Sci. 74, 43-50. doi: 10.1292/jvms.11-0305

Chaiyanan, S., Chaiyanan, S., Grim, C., Maugel, T., Huq, A., and Colwell, R. R. (2007). Ultrastructure of coccoid viable but non-culturable Vibrio cholerae. Environ. Microbiol. 9, 393-402. doi: 10.1111/j.14622920.2006.01150.x

Chaveerach, P., ter Huurne, A. A., Lipman, L. J., and van Knapen, tion of ten strains of Campylobacter jejuni and Campylobacter coli under acid conditions. Appl. Environ. Microbiol. 69, 711-714. doi: 10.1128/AEM.69.1.711-714.2003

Chen, S. Y., Jane, W. N., Chen, Y. S., and Wong, H. C. (2009). Morphological changes of Vibrio parahaemolyticus under cold and starvation stresses. Int. J. Food Microbiol. 129, 157-165. doi: 10.1016/ j.ijfoodmicro.2008.11.009

Colwell, R. R. (2000). Viable but nonculturable bacteria: a survival strategy. J. Infect. Chemother. 6, 121-125. doi: 10.1007/PL00012151

Colwell, R. R., Brayton, P. R., Grimes, D. J., Roszak, D. B., Huq, S. A. and Palmer, L. M. (1985). Viable but non-culturable Vibrio cholerae and related pathogens in the environment: implications for release of genetically engineered microorganisms. Nat. Biotech. 3, 817-820. doi:

Dinu, L. D., and Bach, S. (2011). Induction of viable but nonculturable Escherichia coli O157: H7 in the phyllosphere of lettuce: a food safety risk factor. Appl. Environ. Microbiol. 77, 8295-8302. doi:

Gangaiah, D., Kassem, I. I., Liu, Z., and Rajashekara, G. (2009). Importance of polyphosphate viable-but-nonculturable cell formation, natural transformation, and antimicrobial resistance. Appl. Environ. Microbiol. 75, 7838-7849. doi: 10.1128/AEM.01603-09

Gangaiah, D., Liu, Z., Arcos, J., Kassem, I. I., Sanad, Y., Torrelles, J. B., etal. (2010). Polyphosphate kinase 2: a novel determinant of stress responses and pathogenesis in Campylobacter jejuni. PLoS ONE 5:e12142. doi: 10.1371/journal.pone. 0012142 F. (2003). Survival and resuscita10.1038/nbt0985-817 10.1128/AEM.05020-11 kinase 1 for Campylobacter jejuni

proper assessment of the impact of VBNC on food safety and public health.

\section{ACKNOWLEDGMENTS}

We thank Tea Meulia, Andrea Kaszas, and the Molecular and Cellular Imaging Center (MCIC) for assistance with TEM. Research in the Gireesh Rajashekara laboratory is supported by funds from the USDA, the Ohio Agricultural Research and Development Center (OARDC), and the Ohio State University.

Grégori, G., Citterio, S., Ghiani, A. Labra, M., Sgorbati, S., Brown, S., et al. (2001). Resolution of viable and membrane-compromised bacteria in freshwater and marine water based on analytical flow cytometry and nucleic acid double staining. Appl. Environ. Microbiol. 67, 46624670. doi: 10.1128/AEM.67.10.46624670.2001

Guillou, S., Leguerinel, I., Garrec, N., Renard, M. A., Cappelier, J. M., and Federighi, M. (2008). Survival of Campylobacter jejuni in mineral bottled water according to difference in mineral content: application of the Weibull model. Water Res. 42, 2213-2219. doi: 10.1016/j.watres.2007.11.035

Heim, S., Lleo, M. D. M., Bonato, B., Guzman, C. A., and Canepari, P. (2002). The viable but nonculturable state and starvation are different stress responses of Enterococcus faecalis, as determined by proteome analysis. J. Bacteriol. 184, 67396745. doi: 10.1128/JB.184.23.6739 6745.2002

Hirshfield, I. N., Terzulli, S., and OByrne, C. (2003). Weak organic acids: a panoply of effects on bacteria. Sci. Prog. 86, 245-269. doi: 10.3184/003685003783238626

Hoffman, P. S., and Goodman, T. G. (1982). Respiratory physiology and energy conservation efficiency of Campylobacter jejuni. J. Bacteriol. 150, 319-326.

Jackson, D. N., Davis, B., Tirado, S. M., Duggal, M., van Frankenhuyzen, J. K., Deaville, D., et al. (2009). Survival mechanisms and culturability of Campylobacter jejuni under stress conditions. Antonie Van Leeuwenhoek 96, 377-394. doi: 10.1007/s10482 009-9378-8

Jang, K. I., Kim, M. G., Ha, S. D., Kim, K. S., Lee, K. H., Chung, D. H., et al. (2007). Morphology and adhesion of Campylobacter jejuni to chicken skin under varying conditions. J. Microbiol. Biotechnol. 17, 202-206.

Jones, D. M., Sutcliffe, E. M., and Curry, A. (1991). Recovery of viable but non-culturable Campylobacter jejuni.
J. Gen. Microbiol. 137, 2477-2482. doi: 10.1099/00221287-137-10-2477

Karmali, M. A. (1989). Infection by verocytotoxin-producing Escherichia coli. Clin. Microbiol. Rev. 2, 15-38. doi: 10.1128/CMR.2.1.15

Kassem, I. I., Khatri, M., Esseili, M. A., Sanad, Y. M., Saif, Y. M., Olson, J. W., et al. (2012). Respiratory proteins contribute differentially to Campylobacter jejuni's survival and in vitro interaction with hosts' intestinal cells. BMC Microbiol. 12:258. doi: 10.1186/1471-2180-12-258

Kassem, I. I., and Rajashekara, G. (2011). An ancient molecule in a recalcitrant pathogen: the contributions of poly-P to the pathogenesis and stress responses of Campylobacter jejuni. Future Microbiol. 6, 1117-1120. doi: 10.2217/ fmb.11.94

Klancnik, A., Guzej, B., Jamnik, P., Vuckoviæ, D., Abram, M., and Mozina, S. S. (2009). Stress response and pathogenic potential of Campylobacter jejuni cells exposed to starvation. Res. Microbiol. 160, 345-352. doi: 10.1016/j.resmic.2009.05.002

Kong, I. S., Bates, T. C., Hülsmann, A., Hassan, H., Smith, B. E., and Oliver, J. D. (2004). Role of catalase and oxyR in the viable but nonculturable state of Vibrio vulnificus. FEMS Microbiol. Ecol. 50, 133-142. doi: 10.1016/j.femsec.2004.06.004

Kornberg, A., Rao, N. N., and Ault-Riché, D. (1999). Inorganic polyphosphate: a molecule of many functions. Annu. Rev. Biochem. 68, 89-125. doi: 10.1007/978-3-64258444-2_1

Krebs, S. J., and Taylor, R. K. (2011). Nutrient-dependent, rapid transition of Vibrio cholerae to coccoid morphology and expression of the toxin co-regulated pilus in this form. Microbiology 157, 2942-2953. doi: 10.1099/mic.0.048561-0

Kusters, J. G., Gerrits, M. M., Van Strijp, J. A., and VandenbrouckeGrauls, C. M. (1997). Coccoid forms of Helicobacter pylori are the morphologic manifestation of cell death. Infect. Immun. 65, 3672-3679. doi: 10.1128/AEM.00047-07 
Kusumoto, A., Miyashita, M., and Kawamoto, K. (2013). Deletion in the C-terminal domain of ClpX delayed entry of Salmonella enterica into a viable but non-culturable state. Res. Microbiol. 164, 335-341. doi: 10.1016/j.resmic.2013.01.011

Lazaro, B., Cárcamo, J., Audícana, A., Perales, I., and FernándezAstorga, A. (1999). Viability and DNA maintenance in nonculturable spiral Campylobacter jejuni cells after long-term exposure to low temperatures. Appl. Environ. Microbiol. 65, 4677-4681. doi: 10.1016/S0167. 7012(03)00025-3

Mascher, F., Moënne-Loccoz, Y., Schnider-Keel, U., Keel, C., Haas, D., and Défago, G. (2002). Inactivation of the regulatory gene algU or gacA can affect the ability of biocontrol Pseudomonas fluorescens CHA0 to persist as culturable cells in nonsterile soil. Appl. Environ. Microbiol. 68, 2085-2088. doi: 10.1128/AEM.68.4. 2085-2088.2002

Medema, G. J., Schets, F. M., van de Giessen, A. W., and Havelaar, A. H. (1992). Lack of colonization of 1 day old chicks by viable, non-culturable Campylobacter jejuni. J. Appl. Bacteriol. 72, 512516. doi: 10.1111/j.1365-2672.1992. tb01868.x

Morgan, T. H. (2010). The Search for a Novel Campylobacter jejuni Resuscitation-promoting Factor. Doctoral thesis, University College London, London. Available at: http://discovery.ucl.ac.uk/642745/

Myers, J. D., and Kelly, D. J. (2004). "Respiratory electron transport in Helicobacter and Campylobacter," in Respiration in Archaea and Bacteria: Diversity of Prokaryotic Respiratory Systems, ed. D. Zannoni (Boston: Kluwer Academic Publishers), 63-77. doi: 10.1007/978-1-40203163-2_3

Nilsson, H. O., Blom, J., Al-Soud, W. A., Ljungh, A., Andersen, L. P., and Wadström, T. (2002). Effect of cold starvation, acid stress, and nutrients on metabolic activity of Helicobacter pylori. Appl. Environ. Microbiol. 68, 11-19. doi: 10.1128/AEM.68.1.1119.2002

Oliver, J. D. (2005). The viable but nonculturable state in bacteria. $J$. Microbiol. 43, 93-100.

Oliver, J. D. (2010). Recent findings on the viable but nonculturable state in pathogenic bacteria. FEMS Microbiol. Rev. 34, 415425. doi: 10.1111/j.1574-6976.2009. 00200.x

On, S. L. W. (1996). Identification methods for campylobacters, helicobacters, and related organisms. Clin. Microbiol. Rev. 9, 405-422. doi: 10.1021/ac990135r

Parkhill, J., Wren, B. W., Mungall, K., Ketley, J. M., Churcher, C., Basham, D., et al. (2000). The genome sequence of the food-borne pathogen Campylobacter jejuni reveals hypervariable sequences. Nature 403, 665668. doi: 10.1038/35001088

Patrone, V., Campana, R., Vallorani, L., Dominici, S., Federici, S., Casadei, L., etal. (2013). CadF expression in Campylobacter jejuni strains incubated under low-temperature water microcosm conditions which induce the viable but non-culturable (VBNC) state. Antonie Van Leeuwenhoek 103 979-988. doi: 10.1007/s10482-0139877-5

Rao, N. N., Gómez-García, M. R. and Kornberg, A. (2009). Inorganic polyphosphate: essential for growth and survival. Annu. Rev. Biochem. 78, 605-647. doi: 10.1146/annurev.biochem.77.083007. 093039

Ricke, S. C. (2003). Perspectives on the use of organic acids and short chain fatty acids as antimicrobials. Poult. Sci. 82, 632-639.

Rollins, D. M., and Colwell, R. R. (1986). Viable but nonculturable stage of Campylobacter jejuni and its role in survival in the natural aquatic environment. Appl. Environ. Microbiol. 52, 531-538. doi: 10.1023/A:1000664013047

Rowan, N. J. (2004). Viable but non-culturable forms of food and waterborne bacteria: Quo Vadis? Trends Food Sci. Technol. 15, 462-467. doi: 10.1016/j.tifs.2004 02.009

Saux, M. F. L., Hervio-Heath, D., Loaec, S., Colwell, R. R., and Pommepuy, M. (2002). Detection of cytotoxin-hemolysin mRNA in nonculturable populations of environmental and clinical Vibrio vulnificus strains in artificial seawater. Appl. Environ. Microbiol. 68, 56415646. doi: 10.1128/AEM.68.11.56415646.2002

Shleeva, M. O., Bagramyan, K., Telkov, M. V., Mukamolova, G. V., Young, M., Kell, D. B., et al. (2002). Formation and resuscitation of 'non-culturable' cells of Rhodococcus rhodochrous and Mycobacterium tuberculosis in prolonged stationary phase. Microbiology 148, 1581-1591. doi: 10.1099/mic.0.26893-0

Smith, B., and Oliver, J. D. (2006). In situ and in vitro gene expression by Vibrio vulnificus during entry into, persistence within, and resuscitation from the viable but nonculturable state. Appl. Environ. Microbiol. 72, 1445 1451. doi: 10.1128/AEM.72.2.1445 1451.2006

Sofos, J. N., and Smith, G. C. (1998). Nonacid meat decontamination technologies: model studies and commercial applications. Int. J. Food Microbiol. 44, 171-188. doi: 10.1016/S0168-1605(98)00136-6

Stern, N. J., Jones, D. M., Wesley, I. V., and Rollins, D. M. (1994) Colonization of chicks by nonculturable Campylobacter spp. Lett. Appl. Microbiol. 18, 333-336. doi: 10.1111/j.1472-765X.1994.tb00882.x

Tangwatcharin, P., Chanthachum, S., Khopaibool, P., and Griffiths, M. W. (2006). Morphological and physiological responses of Campylobacter jejuni to stress. J. Food Prot. 69, 27472753. doi: 10.1007/s10482-0099378-8

Tholozan, J. L., Cappelier, J. M., Tissier, J. P., Delattre, G., and Federighi, M. (1999). Physiological characterization of viable-but-nonculturable Campylobacter jejuni cells. Appl. Environ. Microbiol. 65, 1110-1116. doi: 10.1007/978-1-4757-0271-2_17

Thomas, C., Hill, D., and Mabey, M. (2002). Culturability, injury and morphological dynamics of thermophilic Campylobacter spp. within a laboratory-based aquatic model system. J. Appl. Microbiol. 92, 433-442. doi: 10.1046/j.13652672.2002.01550.x

Vandamme, P., and De Ley, J. (1991). Proposal for a new family, Campylobacteraceae. Int. J. Syst. Bacteriol. 41, 451-455. doi: 10.1099/0020771341-3-451

van de Giessen, A. W., Heuvelman, C. J., Abee, T., and Hazeleger, W. C. (1996). Experimental studies on the infectivity of non-culturable forms of Campylobacter spp. in chicks and mice. Epidemiol. Infect. 117, 463-470. doi: 10.1017/S0950268800059124

van Vliet, A. H., Baillon, M. L. A., Penn, C. W., and Ketley, J. M. (1999). Campylobacter jejuni contains two fur homologs: characterization of iron-responsive regulation of peroxide stress defense genes by the PerR repressor. J. Bacteriol. 181, 63716376. doi: 10.1099/mic.0.27412-0

Weerakoon, D. R., Borden, N. J., Goodson, C. M., Grimes, J., and Olson, J. W. (2009). The role of respiratory donor enzymes in Campylobacter jejuni host colonization and physiology. Microb. Pathog. 47, 8-15. doi: 10.1016/j.micpath.2009.04.009

$\mathrm{Xu}$, H. S., Roberts, N., Singleton, F. L., Attwell, R. W., Grimes, D. J., and Colwell, R. R. (1982).
Survival and viability of nonculturable Escherichia coli and Vibrio cholerae in the estuarine and marine environment. Microb. Ecol. 8, 313323. doi: 10.1007/BF02010671

Yaron, S., and Matthews, K. R. (2002). A reverse transcriptase-polymerase chain reaction assay for detection of viable Escherichia coli O157:H7: investigation of specific target genes. J. Appl. Microbiol. 92, 633640. doi: 10.1046/j.1365-2672.2002. 01563.x

Zandri, G., Pasquaroli, S., Vignaroli, C., Talevi, S., Manso, E., Donelli, G., et al. (2012). Detection of viable but nonculturable staphylococci in biofilms from central venous catheters negative on standard microbiological assays. Clin. Microbiol. Infect. 18, E259-E261. doi: 10.1111/j.14690691.2012.03893.x

Ziprin, R. L., Droleskey, R. E., Hume, M. E., and Harvey, R. B. (2003). Failure of viable nonculturable Campylobacter jejuni to colonize the cecum of newly hatched leghorn chicks. Avian Dis. 47, 753-758. doi: 10.1637 /7015

Ziprin, R. L., and Harvey, R. B. (2004). Inability of cecal microflora to promote reversion of viable nonculturable Campylobacter jejuni. Avian Dis. 48, 647-650. doi: 10.1637/7153010504R1

Conflict of Interest Statement: The authors declare that the research was conducted in the absence of any commercial or financial relationships that could be construed as a potential conflict of interest.

Received: 10 April 2013; accepted: 18 June 2013; published online: 09 July 2013.

Citation: Kassem II, Chandrashekhar K and Rajashekara G (2013) Of energy and survival incognito: a relationship between viable but non-culturable cells formation and inorganic polyphosphate and formate metabolism in Campylobacter jejuni. Front. Microbiol. 4:183. doi: 10.3389/fmicb.2013.00183

This article was submitted to Frontiers in Microbial Physiology and Metabolism, a specialty of Frontiers in Microbiology. Copyright (c) 2013 Kassem, Chandrashekhar and Rajashekara. This is an open-access article distributed under the terms of the Creative Commons Attribution License, which permits use, distribution and reproduction in other forums, provided the original authors and source are credited and subject to any copyright notices concerning any thirdparty graphics etc. 